\title{
Cartografando a construção do atual perfil de leitor de textos literários egresso das aulas de língua portuguesa do ensino médio*
}

RODRIGO ALVES DOS SANTOS

Centro Federal de Educação Tecnológica de Minas Gerais, Divinópolis, MG, Brasil

\section{RESUMO}

Este texto se detém sobre alguns dos documentos reguladores da disciplina de língua portuguesa oferecida nas escolas de ensino médio do Brasil: Parâmetros Curriculares Nacionais (1999); PCN+ ensino médio (2002) e as Orientações curriculares para o ensino médio (2006). Busca-se uma resposta à questão: quais as (re)configurações do perfil do aluno-leitor de textos literários a ser entregue pela escola regular à sociedade? Constata-se que o egresso da escola de nível médio, então nomeado como um leitor crítico de textos literários, teve o seu perfil formatado nos textos oficiais aqui analisados, sendo resultado de uma engenhosa articulação de concepções e saberes que, na trama do poder/saber, permitiram sua "natural" aparição na configuração atual da disciplina de língua portuguesa do ensino médio.

\section{PALAVRAS-CHAVE}

discursos oficiais; leitor de textos literários; ensino médio.

* Texto produzido com base em pesquisas realizadas com apoio do Programa Alban (Programa de Bolsas de Alto Nível da União Europeia para a América Latina) e da Fundação de Amparo à Pesquisa do Estado de Minas Gerais (FAPEMIG). 


\title{
MAPPING THE CONSTRUCTION OF THE CURRENT PROFILE OF READERS OF LITERARY TEXTS GRADUATING FROM BRAZILIAN SECONDARY SCHOOL PORTUGUESE LANGUAGE CLASSES
}

\begin{abstract}
This text holds on some of the regulatory documents of the Portuguese Language course offered in high schools in Brazil: Parâmetros Curriculares Nacionais (1999); PCN+ ensino médio (2002), and Orientações curriculares para o ensino médio (2006). It seeks to answer the question: what are the (re) student-reader's profile to be delivered by regular school to brazilian society? Notes that the graduate of the high school, then appointed as a critical reader of literary texts, had its profile formatted in official texts analyzed here, being the result of an ingenious articulation of ideas and knowledge that in the power plot / namely, allowed their "natura" appearance on the current configuration of the discipline of Portuguese high school language.
\end{abstract}

KEYWORDS

official speeches; reader of literary texts; brazilian high school.

\section{CARTOGRAFIANDO LA CONSTRUCCIÓN DEL ACTUAL PERFIL DEL LECTOR DE TEXTOS LITERARIOS EGRESADO DE LAS CLASES DE LENGUA PORTUGUESA DE LAS ESCUELAS SECUNDARIAS}

\section{RESUMEN}

Este texto aborda algunos documentos reguladores de la disciplina de lengua portuguesa ofrecidos en las escuelas secundarias en Brasil: Parâmetros Curriculares Nacionais (1999); PCN+ ensino médio (2002) y Orientaçôes curriculares para o ensino médio (2006). Es una búsqueda de una respuesta a la pregunta: ¿Cuáles (re)configuraciones del perfil del alumno-lector de textos literarios para ser entregado por la escuela secundaria a la sociedad brasileña? Observase que el perfil del estudiante educado en las clases de las escuelas secundarias de idioma portugués, designado como un lector crítico de los textos literarios, es formateado en textos oficiales aquí analizados como el resultado de una ingeniosa articulación de conceptos y conocimientos que permitieron que su aspecto "natural" en la configuración actual de la disciplina de la lengua portuguesa de la enseñanza secundaria.

PALABRAS CLAVE

los discursos oficiales; lector de textos literários; educación secundaria. 


\section{PALAVRAS INICIAIS}

O presente trabalho se detém sobre alguns dos documentos reguladores da disciplina de língua portuguesa oferecida nas escolas regulares de ensino médio do Brasil: Parâmetros Curriculares Nacionais (Brasil, 1999), PCN+ ensino médio (Brasil, 2002) e as Orientaçóes curriculares para o ensino médio (2006), textos centrais quando se busca entender a configuração atual dessa disciplina escolar nos anos finais da educação básica do país.

Neste texto, o retorno a esses documentos representativos da reforma educacional que se almeja empreender no país desde os anos de 1990 se dá pela busca por uma resposta à seguinte questão, quando se pensa na formação de leitores jovens em ambiente escolar: quais as (re)configurações do perfil do aluno-leitor de textos literários a ser entregue pela escola regular à sociedade?

$\mathrm{O}$ argumento que fundamenta as discussões aqui apresentadas considera que, no discurso oficial que dá forma à disciplina escolar de língua portuguesa na passagem do antigo segundo grau para o atual ensino médio, uma série de micromudanças veio sendo arquitetada. Mudanças estas delicadamente engendradas na legislação oficial de modo que pudesse garantir que o perfil do aluno-leitor de textos literários egresso da educação básica regular esteja, ao menos ao nível do discurso, alinhado com as demandas estabelecidas pelos novos desenhos socioeconômicos e estruturais impostos ao cidadão do século XXI.

Hoje já é consenso que os documentos eleitos como objeto para essa reflexão (doravante denominados PCN, PCN+ e Orientações Curriculares Nacionais), cada qual a seu modo, terminaram por tratar da indicação de conteúdos, de formas de abordagem dos temas e assuntos tratados, de opções metodológicas de ensino, de suportes teóricos autorizados, de conceitos a serem fixados, de saberes e comportamentos a serem "ensinados", de sujeitos pedagógicos desejados e, ainda, de formas comportamentais prescritas para esses sujeitos, sendo eles professores ou alunos. São textos que, por isso, inscreveram-se rapidamente na discursividade da educação, campo que constitui, há tempos, uma forma eficaz "de manter e modificar a apropriação dos discursos, com os saberes e os poderes que eles comportam" (Foucault, 1996, p. 43-44). Exatamente por isso, esses documentos tiveram (e ainda têm) capital importância na constituição do que se veio configurando, nas últimas décadas, como parâmetro do que se espera em relação à formação de leitores em ambiente escolar frequentado por jovens.

Neste trabalho, o discurso veiculado nos documentos oficiais é considerado uma prática (Foucault, 1995, 1996). Isso significa que ele é tomando não como representação das coisas, dos objetos, dos sujeitos de que trata, mas como espaço de produção deles. Em sendo assim, seguindo na direção apontada pelos deslocamentos feitos pelo filósofo francês Michel Foucault no trato com o discurso e também por reflexões sobre a análise de discursos por uma perspectiva foucaultiana (Almeida, 2006; Fischer, 2001; Gregolin, 2007; Paraíso, 2007; Sargentini e Navarro-Barbosa, 2004), a análise da qual resulta este texto buscou significar não o que o discurso nele veiculado ocultava, mas sim o que produzia, fabricava quando tratava do leitor de textos literários a ser "formado" nas aulas de língua portuguesa do chamado novo ensino médio. 
Considerando, portanto, esse enquadramento teórico, esta reflexão encontra-se assim organizada: primeiro, faz-se um percurso analítico-reflexivo apresentando concepções que davam sustentabilidade à abordagem dos textos literários na disciplina de língua portuguesa do antigo segundo grau e apontando as transformações impostas a essas concepções para que um novo perfil de leitor jovem egresso da educação formal pudesse ser erigido sobretudo a partir dos anos 1990. Feito isso, passa-se a uma leitura analítica dos PCN e dos documentos dele derivados considerando que se encontram evidências de que uma outra feição identitária passou a ser configurada para os alunos concluintes da etapa de educação formal obrigatória do país, no que se refere à leitura de textos literários.

\section{A PASSAGEM DO (ANTIGO) SEGUNDO GRAU PARA O (NOVO) ENSINO MÉDIO: CONSTRUINDO AS CONDIÇÕES DE EMERGÊNCIA DE UM NOVO PERFIL DE EGRESSO DA DISCIPLINA DE LÍNGUA PORTUGUESA}

Segundo o parecer n. 853, de 12 de novembro de 1971, que fixava as disciplinas do núcleo comum para os currículos de primeiro e segundo graus, a língua portuguesa no ensino formal de então deveria ser:

encarada como instrumento de comunicação no duplo sentido da transmissão e compreensão de ideias, fatos e sentimentos sob a dupla forma oral e gráfica, o que vale dizer: leitura, escrita e comunicação. (Brasil, 1971a, p. 13)

Segundo esse preceito, leitura, escrita e comunicação, nesse contexto, tinham, na disciplina em causa, o objetivo de formar um sujeito discente que dominasse a norma culta não só na escrita, mas também na oralidade.

Ainda segundo o mesmo documento, a orientação metodológica para o ensino da língua portuguesa era a de se tomar como ponto de partida o "saber linguístico prévio" do aluno (Brasil, 1971a, p. 13), no primeiro grau, até chegar, a partir das séries finais dessa parte da Educação Formal, “às sistematizações gramaticais [...] para ordenar as experiências assim colhidas [no mundo extraescolar]" (Brasil, 1971a, p.13). Assim, mesmo que se considerasse o conhecimento da língua materna que o aprendiz trazia de casa e do mundo extraescolar, era papel da matéria escolar de língua portuguesa "orientar e disciplinar" tal saber de modo que atingisse os objetivos da disciplina em relação àquilo que o egresso deveria dominar (Brasil, 1971a, p. 13).

Nesse contexto, a literatura, para além da função de fixar uma desejada identidade nacional assumida desde o contexto pós-Independência do país, deveria ser tomada como uma forma de colocar os alunos em contato com os "bons exemplos de uso da língua materna", tal qual ocorrera com o ensino do grego e do latim dos tempos de outrora. Ou seja, a leitura literária, para além da fixação da identidade nacional, atendia, no antigo segundo grau, a uma função utilitarista que, uma vez sob mira dos discursos acadêmicos acerca do ensino da língua materna, passaria a ser objeto de considerável crítica. Exemplo disso pode ser notado no fato de que desde a publicação de obras como A leitura e o ensino da literatura, de Zilberman 
(1988), até a aparição recente de trabalhos como o de Ivanda Martins (2006), essa "abordagem utilitarista" da literatura na escola, em especial como pretexto para o ensino de gramática, vem sendo, no Brasil, objeto de uma contundente crítica dos estudiosos do assunto.

Com as mudanças nos objetivos da educação média vislumbradas a partir de meados dos anos de 1990 e a consequente modificação do perfil de egresso da escola regular desejado - somadas às críticas ao uso utilitário da literatura em contexto escolar -, deixou de ter sentido, no discurso regulador e configurador da educação formal do país, a exigência de que o egresso da disciplina de língua portuguesa dos anos finais dessa educação regular se limitasse a ser o jovem que dominava a norma culta padrão na escrita e na fala.

O aluno, já nos advertira Gimeno Sacristán (2003), é uma invenção social dos adultos das sociedades escolarizadas para, entre outros fatores, organizar a vida dos não adultos. Dessa maneira, ainda de acordo com o autor, à volta dessa categoria - o aluno - forma-se toda uma ordem social que obriga os nela enquadrados a agir de determinado modo. Nesse sentido, comenta Almeida (2006, p. 248), em diálogo com Gimeno Sacristán (2003), "o aluno da Modernidade é uma categoria associada ao menor de idade, aquele que, ao longo do século XX, incorporou e passou a ser objeto das visões que a psicologia e a as ciências sociais projetaram para ele". Assim sendo, uma das convenientes características atribuídas ao aluno inventado nesse contexto era a condição de passividade na recepção do saber escolarizado, a qual, pelo que se percebe, seria condenada pelo discurso aqui analisado.

Com o advento do chamado novo ensino médio, um outro perfil de aluno-leitor passou a ser desejado - no discurso acerca da educação formal no Brasil, de modo geral, e no que se relacionava à disciplina de língua portuguesa, em particular —, já que, no que se referia a essa disciplina, estavam dadas as condições necessárias para que o leitor passasse a ser o alvo de todo o investimento pedagógico, atendendo a uma antiga orientação dos discursos acadêmicos sobre a leitura e o ensino de língua portuguesa. Nesses termos, no que se referia aos objetivos dessa disciplina, esse não era um objetivo recém-estabelecido - o de formar leitores -, uma vez que o discurso acadêmico brasileiro da década de 1980 já divulgava essa vontade de que o ensino de língua materna passasse a dar mais atenção a essa formação.

Segundo o discurso acadêmico de então, já naquela época se faziam necessárias ações efetivas que instaurassem uma ruptura no "conjunto de restrições agudas" que impedia "a fruição da leitura [...] por milhões de leitores em potencial" (Silva, 1983, p. 16). Na conjuntura do início dos anos de 1980, Ezequiel Teodoro da Silva já afirmava, "figurativamente falando", que "o problema da leitura no contexto brasileiro deve[ria] ser colocado [...] em termos de [uma] lei-dura" (Silva, 1983, p. 16), assim apresentada pelo autor:

$1^{\circ}$ Parágrafo da lei-dura da leitura: somente a elite dirigente deve ler; o povo deve ser mantido longe dos livros. Os livros, quando bem selecionados e lidos, estimulam a crítica, a contestação e a transformação - elementos estes que colocam em risco a estrutura social vigente e, portanto, o regime de privilégios. [...] 
$2^{\circ}$ Parágrafo da lei-dura da leitura: no território nacional, os diferentes aspectos da leitura devem permanecer como pontos de interrogação. $\mathrm{O}$ apoio à execução de pesquisas e ao desenvolvimento de programas, visando à mudança, deve ser o mínimo possível de modo que as coisas permaneçam como estão. [...] $3^{\circ}$ Parágrafo da lei-dura da leitura: o ensino da leitura, como proposto pelas escolas, deve ser feito pelo processo de ensaio-e-erro. Deve, é claro, haver mais erros que acertos de modo a confundir o aluno-leitor. Não o gosto, mas o "desgosto" pela leitura deve ser incentivado. Mesmo o professor, por falta de condições, deve ser impedido de ler criticamente. [...]

$4^{\circ}$ Parágrafo da lei-dura da leitura: os diferentes especialistas que fazem ciência na área da leitura devem trabalhar de forma não integrada ou compartimentalizada. A visão do todo, estabelecida através da integração de perspectivas diversas (histórica, política, comunicacional, literária, psicológica, linguística, etc...) é sempre perigosa e deve ser sempre evitada — os conhecimentos relativos à leitura no Brasil devem aparecer e serem disseminados na forma de "retalhos". (Silva, 1983, p. 16-19, grifos do autor)

Da mesma forma, ainda em relação à centralidade a ser dada à leitura e à formação do leitor manifestada pelo discurso acadêmico no Brasil já no início dos anos de 1980, consagradas ficariam as palavras de Paulo Freire, registradas em A importância do ato de ler:

refiro-me a que a leitura do mundo precede sempre a leitura da palavra e a leitura desta implica a continuidade daquele. [...] De alguma maneira, porém, podemos ir mais longe e dizer que a leitura da palavra não é apenas precedida pela leitura do mundo, mas por uma certa forma de "escrevê-lo" ou de "reescrevê-lo", quer dizer, transformá-lo através de nossa prática consciente. (Freire, 1989, p. 20)

Dessa maneira, o desejo do discurso acadêmico pela centralidade por uma focalização na leitura e na formação do leitor na disciplina de língua portuguesa passou a ser alicerçado por argumentos como:

[...] é importante que as classes menos favorecidas tenham acesso à cultura letrada, sob pena de se manterem as diferenças sociais. Isso quer dizer que, ao se valorizar todas as expressões culturais dominadas, não se está pretendendo limitar as classes populares ao conhecimento já adquirido no grupo. O que se propõe abrir-lhes o leque de opções de modo a atuar efetivamente na vida social e não apenas como massa de manobra, uma vez que elas passam a ser capazes de jogar com as mesmas armas. (Aguiar e Bordini, 1988, p. 12)

Ganhava força, assim, no discurso acadêmico em favor de uma mudança de perspectiva na disciplina de língua portuguesa, uma vontade emancipatória, transformadora, revolucionária, libertadora (que tão bem caracterizaria as pedagogias críticas então em voga). Segundo tal vontade, o foco da disciplina escolar deveria 
ser a formação do leitor, e não apenas de alguém que viesse a dominar a língua culta, como se aspirava na disciplina de língua portuguesa do segundo grau. A essa demanda instaurada pela postura acadêmica dos anos de 1980 viria, portanto, se adequar o "novo projeto pedagógico" para os anos finais da educação formal do país, buscando fabricar o cidadão consciente e protagonista de sua existência, características essenciais de um perfil de cidadão que muito seria desejado no século XXI.

Consolidados os argumentos mencionados acerca do papel da disciplina de língua portuguesa em contexto escolar, não foi surpresa quando os posicionamentos, também já mencionados, facilmente se alinharam com as teorizações em torno do conceito de letramento que ganharam maior visibilidade nos anos de 1990 no Brasil. Foi desse encontro de vontades acadêmicas e políticas de mudança de foco na disciplina de língua portuguesa que ganhou força a argumentação de que:

socialmente e culturalmente, a pessoa letrada já não é a mesma que era quando analfabeta ou iletrada, ela passa a ter uma condição social e cultural - não se trata propriamente de mudar de nível ou de classe social e cultural, mas de mudar de lugar social, seu modo de viver na sociedade, sua inserção na cultura - sua relação com os outros, com o contexto, com os bens culturais torna-se diferente. (Soares, 2004, p. 37)

Porém não só esses argumentos alimentariam a vontade pedagógica de voltar os esforços no trabalho com a leitura para a formação de leitores no ensino formal do Brasil. No que se refere especificamente à leitura literária, contribuições para isso viriam, mesmo que com menor peso, das teorizações e discussões oriundas dos debates ocorridos no campo dos estudos literários acerca da atenção a ser dada ao leitor, quando do trato com o texto literário.

Conforme afirma Compagnon (2001), os estudos literários sempre dedicaram um "lugar muito variável ao leitor", apresentando, quanto a isso, "posições antitéticas: de um lado, as abordagens que ignoram o leitor, e do outro, as que o valorizam, ou até o colocam em primeiro plano, identificando a literatura à sua leitura" (Compagnon, 2001, p. 139). Ainda segundo esse autor:

a desconfiança em relação ao leitor é — ou foi durante muito tempo — uma atitude amplamente compartilhada nos estudos literários, caracterizando tanto o positivismo quanto o formalismo, tanto o Nerw Criticism quanto o estruturalismo. O leitor empírico, a má compreensão, as falhas da leitura, como ruídos e brumas, perturbam todas essas abordagens, quer digam respeito ao autor ou ao texto. Daí a tentação, em todos esses métodos, de ignorar o leitor ou, quando reconhecem sua presença, [...], a tentação de formular sua própria teoria como uma disciplina da leitura ou uma leitura ideal, visando remediar as falhas dos leitores empíricos. (Compagnon, 2001, p. 143)

Mesmo reconhecendo a existência dessa tentação a que se refere Compagnon, o leitor veio paulatinamente ganhando espaço nas discussões de cunho acadêmico acerca do trato com o texto - de um modo geral - e mais fortemente com o texto 
literário - em particular. Nesse sentido, dois ciclos de debate estrangeiros teriam influência na mudança de rumos a ser operada no perfil do egresso da disciplina de língua portuguesa do ensino médio: primeiro, Stanley Fish, com seu conceito de comunidades interpretativas; segundo, os desdobramentos dos estudos da estética da recepção. No que se refere ao primeiro, cabe lembrar que

o termo comunidade interpretativa diz respeito a um sistema ou contexto capaz de produzir o consenso em torno da escolha da interpretação a ser atribuída a um enunciado ou conjunto de enunciados. [...] Tal como formula Stanley Fish, se a interpretação pode ser intersubjetivamente compartilhada, isto não ocorre por haver uma estabilidade de significados inerente à textualidade, mas por existirem estratégias de leitura disponíveis, passíveis de serem compartilhadas dentro de uma comunidade. [...] Comunidade interpretativa é, portanto, aquele ponto de intersecção a partir do qual se constrói uma certa estabilidade significativa, a partir do momento em que os indivíduos que ali se agrupam compartilham regras e estratégias de leitura que emolduram a aceitabilidade interpretativa e que permitem a comunicabilidade, o intercâmbio e a coincidência de interpretações. (Ceia, 2015, s/p.)

Já em relação ao grupo de teóricos que ficou conhecido pelo jargão estética da recepção no Brasil, cabe destacar que eles defendiam "a soberania do leitor na recepção crítica da obra de arte literária”, em particular Hans Robert Jauss, "o mais inflexível dos críticos da estética da recepção"(Ceia,2015, s/p.). Mesmo que toda essa discussão oriunda do campo dos estudos literários no estrangeiro tenha influenciado a dos objetivos a serem alcançados no trabalho com a leitura literária na educação formal do país, fato que, em âmbito nacional, tal mudança ocorreu mesmo pela intensidade das argumentações feitas pelos autores nacionais antes mencionados.

Conectadas as vontades da pedagogia crítica dos anos 1980 às condições anteriormente mencionadas, e, contando, ainda, com o suporte dado pelas teorizações do letramento, o foco da disciplina escolar de língua portuguesa voltar-se-ia, assim, para a formação de um leitor cujo perfil não implicaria uma mera mudança de atitude em um sujeito pedagógico (no caso, um aprendiz da língua materna), mas uma transformação de um modo de existência, já que o que se almejava, com a nova educação formal, era a formação de um desejado cidadão consciente.

\section{DOS PARÂMETROS CURRICULARES NACIONAIS ÀS ORIENTAÇÕES CURRICULARES DE LIINGUA PORTUGUESA PARA O ENSINO MÉDIO: A EMERGÊNCIA DO LEITOR CRÍTICO DE TEXTOS LITERÁRIOS}

Como se sabe, a publicação dos PCN, na segunda metade da década de 1990, teve por objetivo inicial nortear os currículos do ensino fundamental e médio em todo o território nacional, representando um importante passo no projeto, então emergente, de promover uma reordenação na educação nacional depois do que se convencionou chamar de década perdida, os anos de 1980. A despeito da impor- 
tância desse documento para a configuração das atuais finalidades e intenções do ensino de língua materna nos espaços escolares do país, não foi no texto dele que o perfil de leitor egresso das aulas de língua portuguesa do novo ensino médio apareceu em definitivo. No entanto, os PCN de língua portuguesa do chamado novo ensino médio declaravam já na apresentação o que deveria vir a ser a disciplina de língua portuguesa, que o aluno dos anos finais da educação básica deveria

ser considerado como um produtor de textos, aquele que pode ser entendido pelos textos que produz e que o constituem como ser humano. O texto só existe na sociedade e como produto de uma história social e cultural, único em cada contexto, porque marca o diálogo entre interlocutores que o produzem e entre os outros textos que o compõem. O homem visto como um texto que constrói textos. (Brasil, 1999, p. 139)

Como evidenciado no citado do documento, o sujeito aprendiz desejado para a nova configuração da disciplina de língua portuguesa do ensino médio não era mais o mesmo de outrora. Visto como "um texto que constrói textos" (Brasil, 1999), o aluno do novo ensino médio, segundo a argumentação dos PCN de língua portuguesa, deixaria de ser um mero decifrador de códigos e passaria a ser "um fazedor de significados" (Sim-Sim, 2006, p. 35) tanto na escrita quanto na leitura, promovidas em situação escolar. Ou seja, tanto quando lesse ou escrevesse, o aluno, nessa concepção, estaria produzindo textos que seriam resultado de uma infinidade de fatores de ordem sociocultural, como o próprio aprendiz também o seria.

Desse modo, no discurso oficial de então, assim deveria ser a "nova" aula de língua portuguesa: um "encontro de textos" oriundos de vários universos. Nela, encontrar-se-iam textos-palavras e textos-homens, cada qual com suas histórias, com suas trajetórias, suas concepções. O processo de aprendizagem, nessa perspectiva, poderia ser posto como um ajustamento de fronteiras e entendimentos dos textos-mundo que se encontrariam na aula de português: texto-professor, texto-palavra e texto-aluno.

No entanto, por mais que já esboçassem uma preocupação com a inserção da literatura na área de leitura, os PCN de língua portuguesa do ensino médio, pelo próprio caráter de diretrizes que assumiam, não desenvolviam a temática da formação de leitores como a finalidade principal dessa disciplina. Sempre que se referiam à concepção de aluno como um "texto que constrói textos", os parâmetros aludiam tanto à escrita quanto à leitura.

$\mathrm{Na}$ publicação que se seguiria aos $\mathrm{PCN}$ é que se enunciaria claramente uma mudança quanto ao aluno egresso da disciplina de língua portuguesa dos anos finais da novva educação básica. Nesse sentido, a orientação dos PCN+ seria a de que, no novo ensino médio, dar-se-ia "especial atenção à formação de leitores, inclusive das obras clássicas da nossa literatura" (Brasil, 2002, p. 71, grifos do autor), de modo que pudesse "desenvolver no aluno [...] sua capacitação como leitor efetivo"(Brasil,2002, p. 55, grifos do autor).

Seria a partir desse documento que, no discurso oficial de então, passaria a ser dada uma importância não só à formação de um leitor, mas a de um leitor de literatura (Brasil, 2002, p. 58) do qual se esperava, por exemplo, a capacidade de 
perceber recursos expressivos de que se valeria um autor para construir seu estilo como nos textos de Guimarães Rosa (Brasil,2002, p. 58) -, mas não só. No discurso aqui estudado, esse leitor também seria capaz de:

[...] reconhecer e respeitar produtos culturais tão distintos quanto um soneto árcade ou um romance urbano contemporâneo. (Brasil, 2002, p. 63)

[...] saber identificar obras com determinados períodos, percebendo-as como típicas do seu tempo ou antecipadoras de tendências. (Brasil, 2002, p. 65)

E, ainda, de:

- Distinguir texto literário de texto não literário, em função da forma, finalidade e convencionalidade.

- Comparar dois textos literários, percebendo semelhanças e diferenças decorrentes do momento histórico da produção de cada um deles.

- Diferenciar, em textos, marcas de valores e intenções de agentes produtores, em função de seus comprometimentos e interesses políticos, ideológicos e econômicos.

- Identificar, na leitura de um texto literário, as implicações do tratamento temático e do estilo relativas ao contexto histórico de produção e de recepção do texto.

- Relacionar o universo narrativo com o estilo de época, bem como com os estereótipos e clichês sociais. (Brasil, 2002, p. 80)

Nota-se, assim, que o leitor de textos literários fabricado no discurso em causa afastar-se-ia e, com considerável distância, daquele sujeito discente desejado pelas orientações fundamentadas na Lei de Diretrizes e Bases Nacionais de 1971 (Brasil, 1971b), nas quais o mérito do egresso da disciplina de língua portuguesa era o de dominar a norma culta e reconhecer a língua portuguesa como expressão da cultura brasileira (Brasil, 1971a, p. 12).

No entanto, mesmo que esta última publicação mencionada já tivesse dado considerável centralidade à questão da formação do leitor de textos literários, só nas Orientações Curriculares Nacionais, publicadas em 2006, esse novo egresso da disciplina de língua portuguesa - o leitor de textos literários - teria o seu perfil mais bem refinado. Nessa publicação, ele ganharia um qualificador, passando a ser definitivamente nomeado como um leitor crítico de textos literários. Tal adjetivo crítico -, tal qual assumido pelo próprio discurso oficial de então, seria buscado nas teorizações e posicionamentos de Eco $(1969,1986,1989,1993,1994,2003)$ :

Umberto Eco identifica dois tipos básicos de leitores. “O primeiro é a vítima designada pelas próprias estratégias enunciativas, o segundo é o leitor crítico, que ri do modo pelo qual foi levado a ser [a] vítima designada" (ECO, 1989, p. 101). Quer dizer, o leitor vítima em princípio seria aquele mais interessado em "o que" o texto conta, uma vítima do enunciado, e o leitor crítico em "como" o texto narra, também interessado no modo de enunciação. (Brasil, 2006, p. 68) 
E, dando continuidade à justificava para a formação de um leitor crítico:

Não obstante a multiplicidade e os diferentes níveis de leitura, um leitor crítico pode ser, pois, também um leitor vítima. Entretanto, pode um leitor predominantemente vítima ser um leitor crítico? Sobretudo, poderá ele ser um leitor de obras complexas e mais elaboradas esteticamente? Como leitores críticos, adquirimos a enorme liberdade de percorrer um arco maior de leituras, o que faz toda a diferença. Qual o perigo de sermos leitores vítimas? O perigo é consumirmos obras que busquem agradar a um maior número de leitores, oferecer ao leitor uma gama já consumida de elementos, aquela literatura voltada para o consumo de que falamos, desprovida de potencial para reflexão, que apenas confirma que apenas confirma o que já sabemos, e que, por isso, sacia nossa necessidade mais imediata de fantasia. (Brasil, 2006, p. 69)

Até, na sequência da argumentação, chegar à constatação de que:

E na escola? Que leitor formar? Evidentemente, qualquer pessoa comprometida com a educação logo pensará que compete à escola formar leitores críticos, e esse tem sido, efetivamente, o objetivo perseguido nas práticas escolares, amparadas pelos discursos teóricos da linguagem e pelos documentos oficiais nas últimas décadas. (Brasil, 2006, p. 69)

Dos três documentos aqui considerados (PCN, $\mathrm{PCN}+$ e Orientações Curriculares Nacionais) apenas o último possuía um capítulo especificamente dedicado aos "Conhecimentos de Literatura" (Brasil, 2006, p. 49-83). Nessa publicação, também diferentemente das outras, reconhecer-se-ia, pela primeira vez, no discurso de configuração do novo ensino médio, que a inclusão da literatura como conteúdo curricular na disciplina de língua portuguesa se devia a pretensões de democratização de uma "esfera de produção cultural, pouco ou menos acessível aos leitores, sobretudo da escola pública, fora do ambiente escolar" (Brasil, 2006, p. 60). Além disso, resgatando-se uma citação do crítico literário Antônio Cândido, extraída do texto "O direito à literatura" (Cândido, 1995), no documento em questão, considerar-se-ia a literatura "como um fato indispensável à humanização" (Brasil, 2006, p. 54).

Sendo um entendimento em muito fundado na tradição humanista cujos valores alimentaria a pedagogia moderna, essa concep̧̧ão humanizadora atribuída tanto à literatura como manifestação artística quanto como saber escolarizado ainda não havia sido ativada na materialidade discursiva aqui estudada. No documento em questão, no entanto, ela aparece com argumentos muito próximos daqueles usados pelas pedagogias críticas com sua vontade libertadora e emancipatória do aprendiz.

Assim, nas Orientações Curriculares Nacionais, ao contrário dos documentos que as antecederam, todo o argumento inicial seria estabelecido em torno do caráter salvacionista que a literatura assumiria para os que seriam "privilegiados" com o acesso a ela. Nesse sentido, a argumentação desenvolvida no documento em questão, tomando como ponto de partida um pedido de desculpas que reconhecia que as especificidades do tratamento do texto literário na disciplina de língua portuguesa não tinham ganhado o espaço merecido nas publicações 
anteriores (Brasil, 2006, p. 49-50), partiria de uma pergunta assim enunciada: "Por que ainda a literatura no currículo do ensino médio se seu estudo não incide diretamente sobre nenhum dos postulados desse mundo hipermoderno?” (Brasil, 2006, p. 52). E, para a pergunta feita, oferecer-se-ia a seguinte resposta:

Nesse mundo dominado pela mercadoria, colocam-se as artes inventando "alegriazinha", isto é, como meio de educação da sensibilidade; como meio de atingir um conhecimento tão importante quanto o científico - embora se faça por outros caminhos; como meio de pôr em questão (fazendo-se crítica, pois) o que parece ser ocorrência/decorrência natural; como meio de transcender o simplesmente dado, mediante o gozo da liberdade que só a fruição estética permite; como meio de acesso a um conhecimento que objetivamente não se pode mensurar, como meio, sobretudo, de humanização do homem coisificado: esses são alguns dos papéis reservados às artes, de cuja apropriação todos têm direito. Diríamos mesmo que têm mais direito aqueles que têm sido, por um mecanismo ideologicamente perverso, sistematicamente mais expropriados de tantos direitos, entre eles até o de pensar por si mesmos. (Brasil, 2006, p. 52-53, grifos do original)

Buscando responder à advertência platônica sobre os perigos de se entregar à arte da palavra (Platão, 2000), essa noção de que o acesso à literatura poderia promover a humanização do indivíduo, então resgatada no discurso aqui analisado, viria a se consagrar entre acadêmicos da área de letras e da educação, teóricos, críticos, professores da educação básica e autores de literatura. Estes, por sua vez, cada vez mais, no que se refere à importância a ser dada à literatura, buscariam justificar os atributos da arte da palavra pela consagrada frase de Roland Barthes (Barthes, 2001). ${ }^{1}$

Mantendo, em todo o seu texto, esse tom salvacionista, as Orientações Curriculares Nacionais buscariam, assim, fixar o aspecto de que o egresso da nova disciplina de língua portuguesa do novo ensino médio não era mesmo demandado pelas antigas orientações sobre o ensino de língua materna como disciplina escolar, nas quais ele era um aprendiz da norma culta. Esse novo egresso objetivado não seria, no discurso aqui analisado, apenas um leitor; como já foi mencionado, seria sim um leitor crítico de textos literários e que, como tal, deveria ser um protagonista da própria aprendizagem para vir a ser protagonista de seu novo modo de existência.

Portanto, no discurso aqui analisado, o abandono, pela disciplina de língua portuguesa do novo ensino médio, do projeto de meramente formar um egresso que dominasse a chamada "língua culta padrão" na escrita e na fala constituía uma aposta necessária - para fabricar o cidadão desejado - e uma justificativa pertinente para emergência do formador de leitores críticos de textos literários, posição de sujeito então criada para que um professor de língua portuguesa viesse a ocupar.

1 As palavras de Barthes às quais o trecho em questão faz menção são: "Se, por não sei que excesso de socialismo ou barbárie, todas as nossas disciplinas devessem ser expulsas do ensino, exceto uma, é a disciplina literária que devia ser salva, pois todas as ciências estão presentes no monumento literário" (Barthes, 2001, p. 18). 


\section{CONSIDERAÇÕES FINAIS}

As disciplinas, lembra Foucault (1996, p. 30), ao reconhecerem no interior dos seus limites proposições verdadeiras e falsas, fundamentam-se na "possibilidade de formular, e de formular indefinidamente, proposições novas", implicando uma "reatualização permanente das regras" (Foucault, 1996, p. 36). Castro (2009, p. 110) ajuda a compreender que em Foucault:

encontramos principalmente dois usos do termo "disciplina". Um na ordem do saber (forma discursiva de controle da produção de novos discursos) e outro na do poder (o conjunto de técnicas em virtude das quais os sistemas de poder têm por objetivo e resultado a singularização do indivíduo). Mas é necessário enfatizar que não são dois conceitos sem relação. Ainda que a questão da disciplina - desde o ponto de vista do poder, isto é, dessa forma de exercício do poder que tem por objetivo os corpos e por objetivo sua normalização — tenha sido a que principalmente ocupou os especialistas e interessou aos leitores, não se pode deixar de lado o uso discursivo do conceito de disciplina. Essa resulta particularmente interessante para iluminar o modo como Foucault concebe as relações entre o saber e o poder.

Neste trabalho, buscamos, com base em uma leitura foucaultiana de três dos principais documentos configuradores e reguladores da disciplina de língua portuguesa do ensino médio, mapear a construção do perfil do egresso da educação básica brasileira, no que esta se refere à leitura de textos literários. Nomeado, para o que nos interessou, como um leitor crítico de textos literários, esse egresso da escola formal de nível médio teve o seu perfil engenhosamente formatado nos textos oficiais aqui analisados, sendo resultado de uma também engenhosa articulação de concepções e saberes acadêmicos que, na trama do poder/saber, permitiram sua "natural" aparição na configuração atual da disciplina de língua portuguesa do ensino médio.

Ao registrarmos a emergência e a consolidação de condições propícias no discurso acadêmico-escolar para o aparecimento e configuração do leitor crítico de textos literários como posição de sujeito a ser ocupada pelo aluno da disciplina de língua portuguesa do ensino médio, buscamos evidenciar como são atuais as palavras de Michel Foucault que abrem este tópico. Explicando: como é possível, com o movimento que fizemos nessa reflexão, observar que a disciplina de língua portuguesa no interior dos seus limites reconhece as proposições falsas ou verdadeiras que lhe são pertinentes, fazendo aparecer novas possibilidades identitárias para o alunado e restringindo outras, então consideradas obsoletas.

Ao contrário do que possa parecer aos desavisados, esse movimento por nós então flagrado não deve apavorar aqueles que temem o alcance da escola como instituição formadora de indivíduos... não deve escandalizar os ortodoxos que porventura virem nessa maleabilidade das disciplinas escolares um risco. Esse flagra deve apenas servir para mostrar que as posições de sujeito que ocupamos, os lugares para os quais a educação formal nos conduz não são eternamente estáveis. E, em sendo assim, é possivel lhes alterar as rotas, as finalidades e os perfis. Logo, é possível, mesmo em uma instituição tão tradicional quanto a escola, haver espaço para existir de outros 
modos. Isso abre para nós, formadores de leitores de textos literários, um mundo de possibilidades: outros autores, outros textos, outras literaturas podem adentrar, portanto, o sagrado espaço da sala de aula... permitindo que outros leitores, leitores diferenciados, sejam formados nos espaço escolar.

\section{REFERÊNCIAS}

Aguiar, V. T.; Bordini, M. G. Literatura: a formação do leitor: alternativas metodológicas. Porto Alegre: Mercado Aberto, 1988.

Almeida, M. C. A. As tecnologias da informação e comunicaşão, os novos contextos de ensinoaprendizagem e a identidade profissional dos professores. Tese (Doutorado em Educação) Faculdade de Psicologia e Ciências da Educação, Universidade do Porto, 2006.

Barthes, R. Aula. Aula inaugural da cadeira de semiologia literária do Colégio de França, pronunciada em 7 de fevereiro de 1977. Tradução e posfácio de Leyla PerroneMoisés. 9. ed. São Paulo: Cultrix, 2001.

Brasil. Parecer n. 853/71, de 12 de novembro de 1971, do CFE. Núcleo comum para os currículos de ensino de $1^{\circ} \mathrm{e} 2^{\circ}$ graus. A doutrina do currículo na lei 5.692. In: Documenta n. 132, Rio de Janeiro, nov. 1971a.

. Lei n. 5.692, de 11 de agosto de 1971. Fixa as Diretrizes e Bases da Educação para o Ensino de $1^{\circ}$ e $2^{\circ}$ graus, e dá outras providências. Diário Oficial da União, Brasília, DF, 12 ago. 1971b. Disponível em: <http:/www.planalto.gov.br/CCIVIL_03/leis/ L5692.htm>. Acesso em: 29 jan. 2016.

. Ministério da Educação. Secretaria de Educação Média e Tecnológica. Parâmetros Curriculares Nacionais: ensino médio. Brasília, DF: Ministério da Educação, 1999.

. Ministério da Educação. Secretaria de Educação Básica. PCN+ ensino médio: orientações educacionais complementares aos Parâmetros Curriculares Nacionais. Linguagens, códigos e suas tecnologias. Brasília, DF: Ministério da Educação, 2002.

.Ministério da Educação. Orientaçôes curriculares para o ensino médio. Linguagens, códigos e suas tecnologias. Brasília, DF: Ministério da Educação, Secretaria de Educação Básica, 2006.

CÂndido, A. "O direito à literatura”. In: Vários escritos. 3. ed. São Paulo: Duas Cidades, 1995.

Castro, E. Vocabulário de Foucault: um percurso pelos seus temas, conceitos e autores. Tradução de Ingrid Muller Xavier. Belo Horizonte: Autêntica Editora, 2009.

Comunidade Inter pretativa. In: Ceia, C. (Org.). E-Dicionário de termos literários. Lisboa: [s.n.]. Disponível em: <http://edtl.fcsh.unl.pt/>. Acesso em: 20 nov. 2015.

Compagnon, A. O demônio da teoria: literatura e senso comum. Tradução de Cleonice Paes Barreto Mourão e Consuelo Fortes Santiago. Belo Horizonte: Editora da UFMG, 2001. Eco, U. Obra aberta: forma e indeterminação nas poéticas contemporâneas. Tradução de Geraldo Gerson de Souza. São Paulo: Perspectivas, 1969.

. Lector in fábula. Tradução de Atílio Cancian. São Paulo: Perpectiva, 1986. . "O texto, o prazer, o consumo". In: . Sobre os espelhos e outros ensaios.

Rio de Janeiro: Nova Fronteira, 1989. p. 100-109. 
Eco, U. Interpretação e superinterpretação. São Paulo: Martins Fontes, 1993. . Seis passeios pelos bosques da fição. São Paulo: Companhia das Letras, 1994. . Sobre algumas funções da literatura. In: . Sobre a literatura.2. ed. Rio de

Janeiro: Record, 2003. p. 12.

Fischer, R. M. B. Foucault e a análise do discurso em educação. Cadernos de Pesquisa, São Paulo: Fundação Carlos Chagas; Campinas: Autores Associados, n. 114, p. 197-223, nov. 2001.

Foucault, M.Arqueologia do saber. Tradução de Luiz Felipe Baeta Neves. Rio de Janeiro: Forense Universitária, 1995.

. A ordem do discurso: aula inaugural do Collège de France, pronunciada em

02 de dezembro de 1970. Tradução de Laura Fraga de Almeida Sampaio. 2. ed. São Paulo: Edições Loyola, 1996.

Freire, P. A importância do ato de ler: em três artigos que se completam. 23. ed. São Paulo: Autores Associados; Cortez, 1989.

Gimeno Sacristán, J. O aluno como invenção. Porto: Porto Editora, 2003.

Gregolin, M. R. Foucault e Pechêux na análise do discurso: diálogos e duelos. 3. ed. São Paulo: Editora Claraluz, 2007.

Martins, I. A literatura no ensino médio: quais os desafios do professor? In: Buzen, C.; Mendonça, M. (Orgs.). Português no ensino médio e formação do professor. São Paulo: Parábola Editorial, 2006. p. 83-102.

Paraíso, M. A. Currículo e mídia educativa brasileira: poder, saber e subjetivação. Chapecó: Argos. 2007.

Platão. A República. In: Platão. Tradução de Enrico Corvisieri. São Paulo: Nova Cultural, 2000. (Coleção Os pensadores).

Sargentini, V.; Navarro-Barbosa, P. (Orgs.). Foucault e os dominios da linguagem: discurso, poder, subjetividade. São Carlos: Claraluz, 2004.

Sim-Sim, I. (Coord.). Ler e ensinar a ler. Porto: Edições Asa, 2006.

Silva, E. T. Leitura \& realidade brasileira. Porto Alegre: Mercado Aberto, 1983.

Soares, M. Letramento: um tema em três gêneros. 2. ed. Belo Horizonte: Autêntica, 2004. Zilberman, R. A leitura e o ensino da literatura. São Paulo: Contexto, 1988.

\section{SOBRE O AUTOR}

Rodrigo Alves dos Santos é doutor em educação pela Universidade Federal de Minas Gerais (UFMG). Professor do Centro Federal de Educação Tecnológica de Minas Gerais (CEFET-MG).

E-mail: rodrigo.alves@cefetmg.br 